\title{
ERRATUM
}

\section{A New Statistical Procedure for Testing Equivalence in Two-Group Comparative Bioavailability Trials}

\author{
Walter W. Hauck, ${ }^{1,3}$ and Sharon Anderson ${ }^{2}$
}

In $J P B$, Vol. 12, No. 1, pp. 83-91, there is an error in the calculation of the test statistic in the Example. The value of $T$ (p. 87) should be -1.761 . The $p$ value (p. 88) then becomes

$$
p=F_{17}(0.655)-F_{17}(-2.867)=0.7341
$$

There is no change in the conclusion regarding the hypothesis of equivalence.

We thank J. Stuart Hunter for bringing this to our attention.

\footnotetext{
'Northwestern University Cancer Center and Department of Community Health and Preventive Medicine, Northwestern University Medical School, Chicago, Ill.

${ }^{2}$ American Critical Care, McGaw Park, Ill, and Department of Epidemiology and Biometry, University of Illinois, School of Public Health, Chicago, Ill.

${ }^{3}$ Address correspondence and reprint requests to Dr. Walter W. Hauck, Northwestern University Cancer Center, Biometry Section, Ward 3-332, 303 E. Chicago Ave., Chicago, IL 60611 .
} 